\title{
Recessive Social Trends in the Coal-Mining Region (on Example of Kuzbass) as a Barrier for Sustainable Development
}

\author{
Elena Morozova ${ }^{1}$, Anna Mukhacheva ${ }^{1}$, Tatiana Dobrydina ${ }^{2, *}$, and Nadezhda Usvyat $^{3}$ \\ ${ }^{1}$ Kemerovo State University, Department of Ecology and Nature Management, 650000, Ulitsa \\ Krasnaya 6, Kemerovo, Russian Federation \\ ${ }^{2}$ Kemerovo State University, Department of Foreign Languages in Professional Communication, \\ 650000, Ulitsa Krasnaya 6, Kemerovo, Russian Federation \\ ${ }^{3}$ Altai State University, Department of Foreign Languages (Business and Law Profiles), 656049, \\ Prospect Lenina 61, Barnaul, Russian Federation
}

\begin{abstract}
The article is devoted to the analysis of the dynamics of a number of development indicators of Kemerovo region, which reflect the quality of life of the population, for the period from 1999 to 2016, as well as their dependence on the state of the regional economy. The index of the volume of the gross regional product was chosen as a basic economic indicator. The correlation analysis has revealed a high degree of tightness of the direct linear connection between the growth rates of the gross regional product, on the one hand, and the positive environmental changes. The reverse linear dependence is fixed with the indicators of the level of offenses and emissions into the atmosphere. To determine the degree of impact of the economic downturn on the quality of life of the population, the authors' methodology for assessing "the subsidence" of social indicators during the crisis period was used. Its application in comparison with the all-Russian data made it possible to draw a number of conclusions: in Kemerovo region, the problems of unemployment and negative environmental trends are more acute than in the whole country.
\end{abstract}

\section{Introduction}

Crisis phenomena accompany the economic development of any state existing in the market conditions, reflecting in the fall of production and investment volume, slowing down technological growth, innovative development, and expanding sales markets, etc. $[1,2,3]$. However, what is especially important, the crisis phenomena have a negative impact on the lives of ordinary citizens, forcing them to reduce the list of satisfied needs, leading them to a lower level of consumption, welfare, and social well-being, cause concern in their daily lives and contribute to social destabilization in society $[4,5,6,7]$.

\footnotetext{
* Corresponding author: tdobrydina@,rambler.ru
} 


\section{Materials and Methods}

The high level of economic diversification, equal to the "representation" of industries in the regional structure, and the generally high level of economic development, provide the territories with "immunity" before the impact of the economic crisis, including the quality of life of the population. This conclusion was confirmed by the authors on the basis of extensive empirical analysis of economic and social indicators of 12 regions of the Siberian Federal District for 2003-2015 [8,9].

Conversely, low diversification of the region increases the "vulnerability" of the territory to crisis fluctuations, causing a significant decline in both economic and social indicators $[10,11,12]$. The dominated industrialization with great emphasis on the development of the coal mining sector more and more aggravates the situation, "plunging" the regional economy into dependence on the level of demand and the prices of exported raw materials.

However, the level of coal prices can serve for the industrial economy of "monoregions" as a "catalyst" for growth, even against the background of the general economic recession. Therefore, for 2016-2017, the price of coal in the world market increased by about one and a half times: from 61 to 95 dollars per ton for energy brands; from 92 to 165 dollars per ton (by 70\%) for coking coal. The specified level of world prices was last recorded in 2012. The growth in Russian coal production began in the first half of 2017 (approximately by $10-12 \%$ compared to the same period in 2016). Similarly, national exports increased, despite the decline in other sectors [13]. These positive changes were largely due to the enterprises of Kemerovo region, rightfully called the "coal heart of Russia" and often identified with the world's largest Kuznetsk coal basin (Kuzbass).

Kemerovo region is a highly industrialized subject of the Russian Federation, where the branches of the fuel and energy and metallurgical complexes create the basic value of the gross regional product (GRP); and the prospects for regional development directly depend on the coal industry. More than a third of production assets in Western Siberia are concentrated on the territory of Kemerovo region. The main institutional problems in the development of the region's economy are considered to be the merging of business and government, the existence of large monopolies on self-sufficiency, and the weak diversification of property (almost all of the region's assets are owned by several large Russian companies, which slows down the process of innovation). Also in the region, wear of fixed assets (more than 70\%) remains extremely high. The observed growth in the investment in the innovation sphere does not lead to an adequate increase in the output of innovative products, which is associated with an increase in the share of basic research with under-investment of applied ones. Methane extraction from coal seams and a petrochemical complex are developing as new industries of Kuzbass economy.

Regional researchers note the need to move away from extractive specialization in industry towards processing for improving the diversification of the economy and reducing the risks of economic fluctuations of the exoenvironment $[14,15,16]$. At the present time, taking into account the change in the course of the federal authorities in the development of the Russian coal industry with a shift to the east (in particular, in Tyva and Transbaikalian deposits) into the "bypass" of Kuzbass, this direction of economic growth is transformed from a recommendation into a factual constraint.

According to the authors' studies, the degree of the impact of the crisis in Kemerovo region was particularly acute in comparison with other developed regions of the Siberian Federal District in 2009-2013. This trend is still observed now, negatively affecting, in the first instance, the quality of life of the population of the region, the analysis of whose components became the purpose of this article. 


\section{Results and Discussion}

\subsection{Analysis of the dynamics of social and economic development of Kemerovo region}

Let us consider the dynamics of the main social indicators of Kemerovo region in their relations with economic fluctuations over the past 18 years (1999-2016) based on official statistics [13]. The GRP volume index, \%, and (for comparison) the volume index of gross domestic product (GDP) are used to study the economic state of the region. In order to analyze the social development (quality of life of the population), the following 7 basic indicators were taken: unemployment rate, $\%$; real incomes of the population, $\%$ to the previous year; the number of university students per 10,000; the number of doctors per 10,000 ; number of theaters' spectators per 1,000 people; the number of registered offenses per 100,000; emissions of pollutants from stationary sources into the air (tons per capita).

First of all, we are to emphasize that practically during the whole analyzed period, the rates of economic growth in Russia exceeded the growth rates of Kemerovo region economy. The highest excess was recorded in 2012-2013, when the region's GRP showed a pronounced reduction (the "crisis loop") with an almost unchanged GDP level. In 2014, the economy of Kemerovo region, on the contrary, showed a sharp upward trend, which, however, was replaced by an equally pronounced fall in the following year. In general, it can be noted that the economic development of Russia and that of Kemerovo region have similar trends, though, the growth rate of the economy of the coal region is lower, and the amplitude of the crisis is more pronounced (the trends are less stable, more subject to the impact of situational factors such as the price of coal, etc.). The largest "subsidence" in the dynamics of indicators occured in the period of the global financial and economic crisis of 2008.

Also during the last 18 years, higher unemployment rates, multiple excess emissions to the atmosphere compared to the federal level have been observed in Kemerovo region. At the same time, lower rates of income growth of the population, the number of visits to the theaters, and since 2009 a higher level of crime have been registered. The region is also characterized by lower indices of the number of university students and doctors in relative terms.

\subsection{The impact of crisis phenomena on social indicators of Kemerovo region}

The correlation analysis of the interrelation between the economic and social indicators of Kemerovo region has revealed the high closeness of the direct linear interdependence of GRP growth rates and real incomes of the population (0.65) and the number of spectators in the theatres $(0.66)$. The reverse linear dependence has been established with the indicators of the level of offenses (-0.67), and emissions into the atmosphere from stationary sources $(-0.71)$.

To assess the impact of crisis events on the social indicators of Kemerovo region development, the authors have used a self-developed toolkit that was used to assess "the subsidence" of indicators during the 2008 global financial and economic crisis.

The logic of the methodological base is as follows: the increase of most socio-economic indicators until 2008 was replaced by their decrease in 2009-2010 with the subsequent increase from 2011 (taking into account the possibility of the emergence of new crisis waves in 2014-2016) (Figure 1). At the same time, the dependence can be either direct (an increase is replaced by a decrease in the period of the crisis, for example, with the indicator of the population income) and inverse (a decrease is replaced by an increase in the crisis, as with the unemployment indicator). In the latter case, this figure takes on a mirror-like 
inverted view. However, the actual dynamics of specific indicators of the level of economic development and the quality of life is less straightforward.

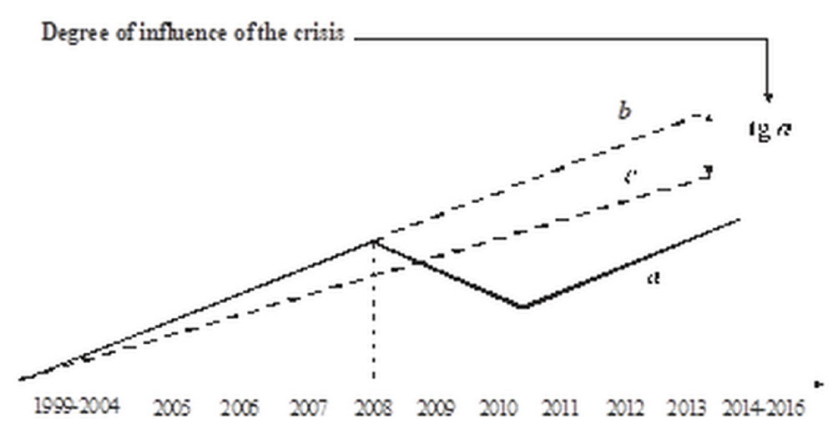

Fig. 1. Analysis of the magnitude of the decrease in social indicators of the region development after the onset of crisis phenomena on the basis of deviation of the actual values of indicators from the forecast values with the continued rates of economic growth: $a$ - actual values of the indicator; $b$ extrapolation line based on the pre-crisis period (1999-2008); c - extrapolation line based on all values of the analyzed period (1999-2016).

The analysis of the changes in the average trends in the dynamics of indicators was carried out in several stages:

- derivation by software methods of the linear equation (trend line) describing the change in the values of indicators in the pre-crisis period (1999-2008);

- extrapolation of the trend line of the pre-crisis period for 2009-2016 to obtain the forecasted data of the indicator with the continued rates of economic growth (construction of line $b$ in Figure 2);

- derivation by software methods of the linear equation (trend line) describing the change in the values of indicators throughout the analyzed period (1999-2016), taking into account their decrease during the crisis (the construction of the line with the average trend in Figure 2);

- calculation of the deviation of the extrapolation line from the pre-crisis period (line b) from the trend line of the actual values for the entire analyzed period (line c) by calculating the tangent of the angle between these lines - the quantitative estimate of the decrease of indicators of economic development and the quality of life in the time of the crisis phenomena.

The indicator of decrease in social and economic indicators - the tangent of the angle between the obtained lines $b$ and $c$ (the values are measured in the range from 0 to 1 ) - is calculated by the formula:

$$
\operatorname{tg} \varphi=\frac{k_{2}-k_{1}}{1+k_{2} \bullet k_{1}}
$$

where $k 2, k 1$ are the coefficients of the parameter $\mathrm{x}$ of the linear extrapolation line equations; $\varphi$ is the angle between the extrapolation lines.

The analysis of the data in Table 1 allows concluding that the degree of negative changes in the rates of economic growth after 2008 compared to the pre-crisis period in Russia is slightly higher than in Kemerovo region. In 2014-2016, there were no significant negative changes in the general trend of economic development in Kuzbass region, unlike the countrywide indicators. 
Table 1. The subsidence of socio-economic indicators of the Russian Federation and Kemerovo region in 1999-2016

\begin{tabular}{|l|c|c|c|c|}
\hline \multirow{2}{*}{ Socio-economic indicators } & \multicolumn{2}{|c|}{$\mathbf{2 0 0 8}$ crisis } & \multicolumn{2}{c|}{$\mathbf{2 0 1 4 - 2 0 1 6}$ crisis } \\
\cline { 2 - 5 } & $\begin{array}{c}\text { Russian } \\
\text { Federation }\end{array}$ & $\begin{array}{c}\text { Kemerovo } \\
\text { region }\end{array}$ & $\begin{array}{c}\text { Russian } \\
\text { Federation }\end{array}$ & $\begin{array}{c}\text { Kemerovo } \\
\text { region }\end{array}$ \\
\hline GRP volume index, \% & 0.578 & 0.475 & 0.042 & $-*$ \\
\hline Level of unemployment, \% & 0.257 & 0.336 & 0.039 & 0.067 \\
\hline $\begin{array}{l}\text { Real incomes of population, \% to } \\
\text { previous year }\end{array}$ & 3.769 & 32.911 & 0.404 & 0.159 \\
\hline $\begin{array}{l}\text { The number of university students per } \\
10,000 \text { people of population }\end{array}$ & 53.648 & 123.576 & 0.331 & - \\
\hline $\begin{array}{l}\text { The number of doctors per 10,000 } \\
\text { people of population }\end{array}$ & 0.270 & 0.317 & 0.184 & 0.338 \\
\hline $\begin{array}{l}\text { The number of theatre spectators per } \\
1,000 \text { people of population }\end{array}$ & - & - & - & - \\
\hline $\begin{array}{l}\text { The number of registered offences per } \\
100,000 \text { people of population }\end{array}$ & 0.103 & 0.004 & - & - \\
\hline $\begin{array}{l}\text { Emissions of pollutants into the } \\
\text { atmosphere, tons per capita }\end{array}$ & - & 0.001 & - & \\
\hline
\end{tabular}

However, the unemployment rate in Kemerovo region against the background of all the crisis phenomena increased significantly more than in most other regions of the Russian Federation. The "collapse" of real incomes of the population in Kuzbass amounted to a multiple in relation to the Russian Federation in 2008, while in 2014-2016 the incomes of the citizens of the region did not decrease as much as the national average.

Also in 2008, a very pronounced decrease in the number of university students and doctors was registered in Kemerovo region. It significantly exceeded the similar indicators in the country. In 2014-2016, there were no obvious negative trends for the first indicator in the region, and for the second indicator the backlog was exacerbated. The number of registered offenses and emissions into the atmosphere slightly changed the trend of the dynamics in 2008; in 2014-2016, the values of the indicators remained unchanged.

\section{Conclusion}

The above analysis indicates a less favourable social development of the coal-mining region in comparison with other subjects of the Russian Federation. The industrial specificity of the territory adversely affects the quality of life of the population, while it does not guarantee stable economic growth.

\section{References}

1. W. Bartlett, M. Uvalić, The Social Consequences of the Global Economic Crisis in South East Europe (London, Jordan Pub., 2010)

2. M. E. Ramona, I. Adrian, C. Ionut, A. M. Violeta, Annals of Faculty of Economics, University of Oradea, 3:1, 252-257 (2009)

3. O. Notta, A. Vlachvei, Procedia - Social and Behavioral Sciences, 175, 350-357 (2015)

4. Ch. Economou, Social Cohesion and Development, 7:1, 5-9 (2012)

5. M. Mihaela, Economic Sciences Series, XIV:2, 212-215 (2014) 
6. V. Skrbinjek, D. Lesjak, J. Šušteršič, Impact of economic crisis on student demand for tertiary education (ML\&TIIM, Bari, 2015)

7. D. G. Gudmundsdottir, Soc. Indic. Res., 110, 1083 (2013)

8. E. Morozova, A. Muhacheva, Regional Differences Assessment in the Level of Economic Development and Life Quality (KemSU, Kemerovo, 2015)

9. A. V. Mukhacheva, E. A. Morozova, European Proceedings of Social and Behavioral Sciences, XXXV, 35 (2018)

10. D. Spacek, P. Dvorakova, European Research Studies Journal, 1, 29-44, (2011)

11. N. N. Mikheeva, Pros and cons. Reg. Res. Russ., 7, 303 (2017)

12. P. Kurecic, G. Kozina, Natural resources management as a factor of underdevelopment and social inequality in the Gulf of Guinea region (ESDC, Zagreb, 2014)

13. Rosstat, Macroeconomic Statistics. URL: http://www.gks.ru/

14. M. Gasanov, S. Zhironkin, Procedia - Social and Behavioral Sciences, 166, 56 (2014)

15. Ph. Sherub, The Possible Risk of Putting All Eggs in One Basket: A Case of Bhutanese (Royal Institute of Management, Bhutan, 2014)

16. S. A. Al-Jundi, Economic Horizons, 33:122, 88-94 (2012) 